
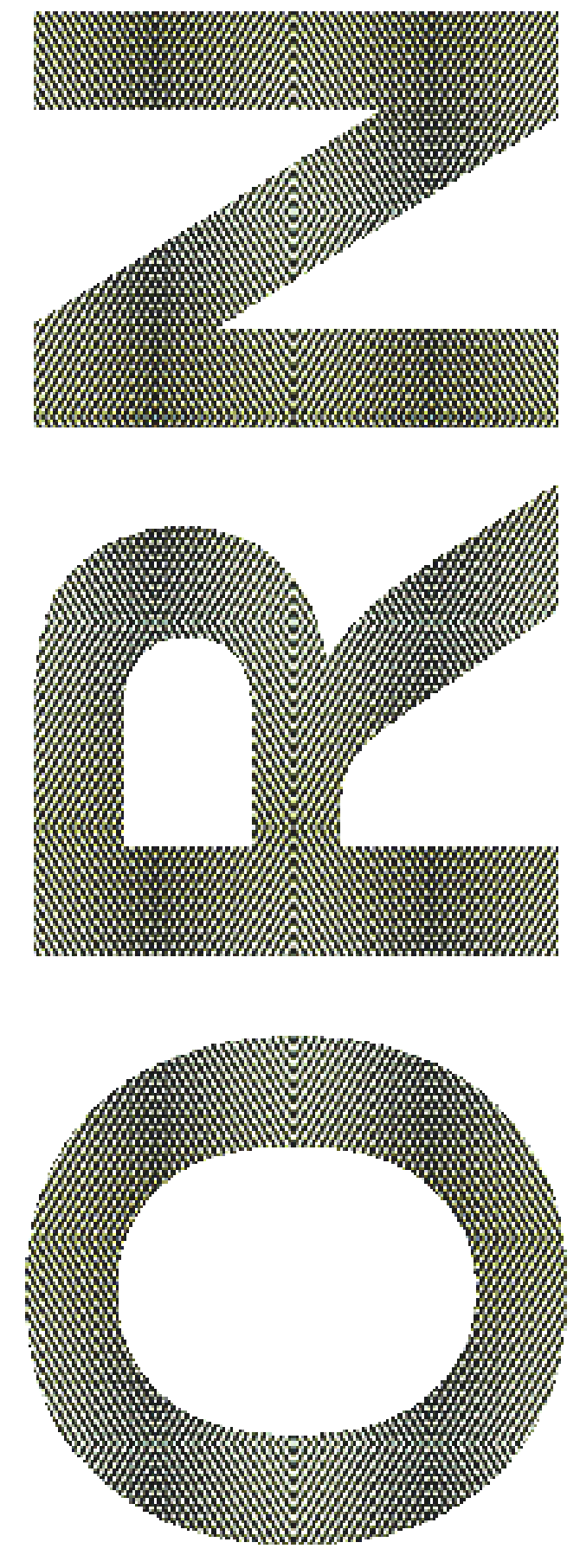

\title{
RING FENCING OF ELECTIVE SURGERY: DOES IT AFFECT HOSPITAL EFFICIENCY?
}

\author{
Terje P. Hagen, Department of Health Management and \\ Health Economics, University of Oslo \\ Lars Erik Kjekshus, SINTEF Health Service Research
}

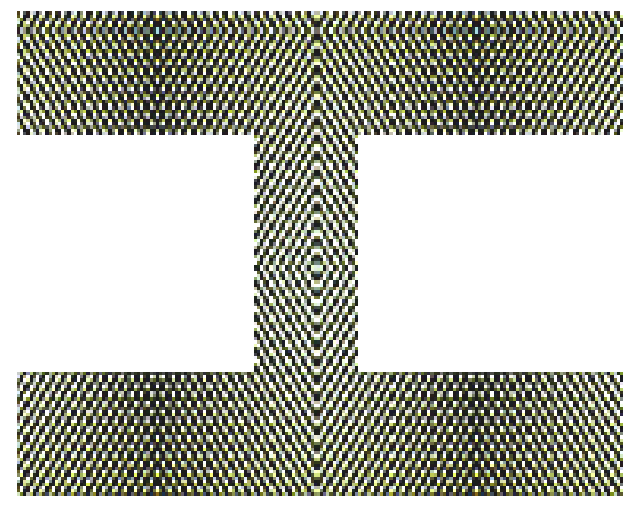

HEALTh ORganization RESEARCH NORWAY - HORN

Working paper 2004 : 4

UNIVERSITY OF OSLO 


\title{
Ring FEnCING Of ELECTIVE SURGERY: DOES IT AFFECT HOSPITAL EFFICIENCY?
}

\author{
Lars Erik Kjekshus a, b, d, * \\ and Terje P. Hagen ${ }^{c, d}$
}

\section{HEALTH ORGANIZATION RESEARCH PROGRAM NORWAY HORN 2004}

\footnotetext{
${ }^{a}$ Department of Health Management and Health Economics, University of Oslo, P.O. Box 1089 Blindern, NO-0317 Oslo, Norway. E-mail: lars.e.kjekshus@,sintef.no

${ }^{\mathrm{b}}$ SINTEF Health Service Research

${ }^{c}$ Department of Health Management and Health Economics, University of Oslo, P.O. Box 1089 Blindern, NO-0317 Oslo, Norway. E-mail: t.p.hagen@medisin.uio.no

${ }^{\mathrm{d}}$ Health Organization Research Program Norway (HORN)

* Corresponding author
} 


\section{Summary}

This study examines the effect of ring fencing in surgical departments. Ring fencing means to shield a surgery unit from interrupting emergency cases. The analysis is performed on two levels. First, an intensive three-month study at the departmental level of three hospitals was performed. It investigates the relationship between the different units involved in a hospital's surgical activity and analyzes the specific units' use of resources and production. Second, a panel data analysis of the organizational population of Norwegian hospitals over the period 1992 to 2000 is conducted, using a "fixed effect" regression model to analyze the effect of ring fencing on a hospital's total cost- and technical efficiency. The study of the three hospitals indicates that ring fencing could have a positive effect on cost- and technical efficiency under the right conditions of case-mix and high demand for elective surgery. However, the analysis of the hospital population shows no particular effect of ring fencing. The models are unstable and are distorted by the exclusion of one of the hospitals. Ring fencing does not seem to have a significant effect on a hospital's general cost-efficiency, but it could have local effects as indicated through the case analysis of three hospitals. Under careful consideration of hospital resources, competencies, case-mix and service demand, ring fencing could be a valuable tool for managers to increase the efficiency of hospitals. 


\section{Introduction}

Cancellations of elective surgery due to incoming emergencies are said to be a source of inefficiency in the surgical departments of hospitals. A review of international studies shows that, $10-17 \%$ of the total number of elective surgical operations are cancelled (Aaserud and Trommald 2001). Norwegian data indicate that $14 \%$ of the cancellations are caused by emergency admissions (Hauge 1999). A solution to this problem is to shield elective surgery from emergencies through so-called "ring fencing". By using ring fencing in parts of the surgical department, a hospital's efficiency may increase through a reduced number of cancellations. This, in turn, may decrease costs through a reduced pre-operational length of stay, extra discharges and the admission of patients who have had their surgery cancelled. Cost-efficiency may also rise due to increased specialization and standardization in the surgical department. In this way, ring fencing can be understood as a special type of organizing elective day-surgery.

The initial concept of ring fenced (RF) units is quite simple and has its roots in industrial production theory and understanding the effects of assembly line production (Mintzberg 1983; Taylor 1911; Ventura and Radhakrishnan 2002). The patient arrives promptly at the top of the corridor and goes through the pre-operation room, operation, recovery, and then leaves at the end of the corridor with a pre-completed medical report in hand. The surgery can be highly specialized. On one particular day, for example, only left-knee operations are performed; the next day, only right-hip operations. In this way, the surgical team will be able to streamline production and the operation theater may be equipped only for the procedures to be handled on that specific day. The process is very similar to assembly line production in car factories. At the end of the corridor the car comes out, fully assembled and newly painted (Monden 1998).

Although RF units are often recommended as a way of increasing efficiency in hospitals (NOU 1997), it has been difficult to actually document the effect of this organizational form. There are several studies that attempt to explain cancellations of elective surgery (Hand, Levin, and Stanziola 1990; Hauge 1999; Jørgensen et al. 
1991; Knight 1987; Lacqua and Evans 1994; Macarthur, Macarthur, and Bevan 1995; Morrissey S, Alun-Jones, and Leighton 1989; Ross and Watson 1988; Wildner et al. 1991). Still, an extensive review of international literature indicates that no Englishlanguage studies have analyzed the effects of RF units on hospital cost-efficiency (Aaserud and Trommald 2001). One study, written in German was found. This study from Lund University Hospital indicates a substantial increase in both the hospital's efficiency and quality of care as a result of the introduction of an RF unit in the surgical department (Hedenbro et al. 2000).

In line with the arguments above, one can hypothesize that the efficiency in an RF unit may be higher than that in ordinary surgical departments. The critical question is, however, not if the efficiency in an RF unit may be higher than in ordinary surgical departments, but whether the introduction of an RF unit affects the total efficiency in the surgical division and the efficiency of the hospital in general. There are two problems that may arise as a result of ring fencing that can affect total efficiency. First, RF units may lead to more "slack" resources in the mixed surgical units (the units with both acute and elective surgery) in periods of few emergency admissions (Aaserud and Trommald 2001). The reason for this is that there might be fewer elective patients in the queue to increase activity during these periods. Second, total efficiency may also be affected if "ring fencing" leads to bottlenecks in other parts of the hospital, more specifically in the service departments. Ring fencing needs a welltuned organization to work to its full potential.

In order to evaluate the effect of ring fencing properly, the effects on total efficiency in the surgical division and/or at the hospital level have to be evaluated. In this study, effects at both the surgical division level and hospital level are examined. First, to gain a better understanding of how RF units affect coordination and efficiency at the department level, a three-month intensive study was conducted in three acute somatic hospitals, two of which had introduced RF units. This study is reported in section 2 of this article. Second, data was collected from all Norwegian somatic acute hospitals on their internal organizational structure, including the existence of RF units. The material was combined with existing data on hospitals budgets, production and efficiency scores generated by data envelopment analysis (DEA). The data was added up to a panel data set consisting of 53 acute hospitals in the period from 1992 to 2000. 
The panel data set formed the basis for statistical tests of the effects of the introduction of RF units in 9 hospitals in the period. The statistical analysis is given in section 3 and the results are reported in section 4 . In section 5 the different aspects of ring fencing are explored and evaluated. The theoretical assumptions is that on part of the organizations are affected by other parts of the organizations(Bertalanffy 1956; Thompson 1967): under what circumstances is ring fencing rational?. How does ring fencing affect the use of personnel? What are alternative ways to organize surgical activity within a hospital? What happens during periods of patient shortage? In the concluding remarks the study findings are summarized and the possible implications of the introduction of RF units are discussed.

\section{A three-month case study in three selected hospitals}

Following recommendations by Yin (Yin 1994), two hospitals with ring fenced surgical units and one hospital without such a unit were chosen for the three-month (January - March 1999) in-depth comparative analysis. The study was restricted to the surgical division. This provided for the development of precise and valid measurements of surgical production and efficiency. The main objective of the indepth study was to describe the different types of ring fenced units, to analyze the interaction between the ring fenced unit and the rest of the surgical division and to compare the production and efficiency between those surgical divisions with ring fenced surgical units and those without.

The three hospitals were all local community hospitals located in the southeast of Norway. In the interest of simplicity, the three hospitals are named B, R and K. Table 1 presents key figures for the three hospitals. 
Table 1 Hospital characteristics, 1999

\begin{tabular}{|c|c|c|c|}
\hline Characteristics: & Hospital K & Hospital R & Hospital B \\
\hline Beds: & 109 (44 surgical beds) & 126 (58 surgical beds) & 224 (103 surgical beds) \\
\hline Man-labor years (total): & 428 & 452 & 952 \\
\hline $\begin{array}{l}\text { Population in the hospital's } \\
\text { catchment area: }\end{array}$ & 49900 & 55800 & 151000 \\
\hline Specialities:* & $\begin{array}{l}\text { Basic specialities and } \\
\text { county speciality in } \\
\text { rheumatology }\end{array}$ & Only basic specialities & $\begin{array}{l}\text { Several county specialities in } \\
\text { addition to basic specialities }\end{array}$ \\
\hline Share of surgical emergencies: & 0.37 & 0.50 & 0.51 \\
\hline Share of day-surgery & 0.36 & 0.53 & 0.43 \\
\hline DRG index:** & 1.04 & 1.01 & 1.07 \\
\hline Mean hospital length of stay:*** & 5.0 & 4.2 & 5.3 \\
\hline $\begin{array}{l}\text { Choice of organizational } \\
\text { solutions in surgical division: }\end{array}$ & $\begin{array}{l}\text { Patient coordinator. } \\
\text { Ordinary operation } \\
\text { theater }\end{array}$ & $\begin{array}{l}\text { Ring fencing in addition } \\
\text { to ordinary operation } \\
\text { theater. Staff on rotation }\end{array}$ & $\begin{array}{l}\text { Ring fencing in addition to } \\
\text { ordinary operation theater. } \\
\text { Staff in regular teams. }\end{array}$ \\
\hline \multicolumn{4}{|c|}{$\begin{array}{l}\text { * Basic specialities are internal medicine, general surgery, general gynaecology and obstetrics, paediatrics, ear, nose, and throat, } \\
\text { anaesthesiology, radiology and laboratory services. County specialities are paediatric surgery, gastroenterological surgery, } \\
\text { vascular surgery, orthopaedic surgery, thoracic surgery, urology, oral surgery and oral medicine, neurosurgery, plastic surgery, } \\
\text { bone/joint and muscle diseases and rehabilitation, dermatology and venerial diseases, sports medicine, haematology, } \\
\text { endocrinology, diseases of the digestive tract, geriatrics, cardiology, infection, thoracic diseases, renal diseases, neurology, } \\
\text { rheumatology, oncology, ophthalmology, tropical diseases, and epidemiology. }\end{array}$} \\
\hline $\begin{array}{l}\text { ** The DRG index is a case-mix inde } \\
0.99 \text {. }\end{array}$ & escribing average patient we & ght in each hospital. The nation & al average in 1999 was \\
\hline
\end{tabular}

In terms of number of beds, hospital B is the largest of the three hospitals in the qualitative study conducted. The average Norwegian hospital (including some small private hospitals) had 183 beds in 1999, whereas hospital B had 224. Hospital B also has the highest share of acute surgery. From the DRG index one can see that hospital $\mathrm{B}$ also performed more complicated interventions than hospitals $\mathrm{K}$ and $\mathrm{R}$. The share of surgery (hospital stays) performed as day-surgery was 0.43 , which is 0.01 above the national average in 1999. Hospital B established an RF unit in 1998. An old outpatient clinic was rebuilt into a service unit, pre-operation room, two new operations theaters, a small recovery unit and two offices. Physicians rotated between the RF unit and other parts of the surgical division while the rest of the staff in the RF unit worked in teams within the unit. 
Hospital R introduced ring fencing in 1997. An old bed section was rebuilt into one pre-operation room, two new operation theaters, a small recovery unit and two offices. The hospital management emphasizes that the RF unit is designed to handle simple procedures that do not require very advanced equipment and can be planned well in advance. The concept is that patients arrive and are discharged on the same day the surgery is performed. However, patients needing extra care are transferred from the RF unit to a recovery unit, intensive care unit or bed sections in the hospital. Both physicians and nurses work on a rotational basis, one week in the RF unit and one to two months in other parts of the surgical division. The rationale behind this rotation of nurses is that it keeps them trained in several areas. The share of daysurgery is relatively high $(0.53)$.

Hospital $\mathrm{K}$ is a small local hospital but with a speciality in complicated cases of rheumatology. The hospital has not established an RF unit but coordinates acute and elective surgery in the same operation theater. As can be seen from Table 1, the share of surgical emergencies is considerably lower for hospital $\mathrm{K}$ than for the other two hospitals. The share of day-surgery, 0.36 , is also lower than the national average.

To analyze the effects of RF units on a surgical division's production and efficiency, data was collected from the finance department and various surgical divisions on hospitals' input factors and production. The following variables form the basis for the indicators used in this analysis:

- DRG_DAY = Produced DRG-equivalents in day-surgery units (including RF units)

- DRG_TOT $=$ Produced DRG-equivalents in the surgery division (including daysurgery units)

- $\quad$ OUT $=$ Revenues (in 1000 NOK) in outpatient clinics

- MM_DAY = Man-labor months in day-surgery units (including RF units)

- MM_TOT = Man-labor months in the surgical division (including day-surgery units)

- MM_OUT $=$ Man-labor months in outpatient clinics

- COST_TOT $=$ Total operating costs (for both inpatients and outpatients) in the surgical division in $1000 \mathrm{NOK}$ 
The number of man-labor months includes man-labor months among physicians, nurses and other involved personnel. Total operating costs are defined as the sum of operating costs in the surgical division, which includes the operation theaters, intensive care units, outpatient clinics, admission units, ER units, anaesthesiology, radiology, sterilization, and laboratory services. COST_TOT includes expenses for wages, medical articles and medicine particular to surgical patients. Expenses for cytostatica treatment are excluded, as well as overhead costs such as hospital administrative costs are not allocated to the surgical division. Descriptive statistics for the variables are shown in Table 2.

Table 2 Descriptive statistics (per month, average over three months)

\begin{tabular}{lrrr}
\hline & Hospital K & Hospital R & Hospital B \\
\hline DRG_DAY & 26.0 & 55.0 & 65.3 \\
DRG_TOT & 181.6 & 298.6 & 595.0 \\
OUT & 204.3 & 248.0 & 627.6 \\
MM_DAY & 7.0 & 8.5 & 11.1 \\
MM_TOT & 136.1 & 190.5 & 324.3 \\
MM_OUT & 5.8 & 10.5 & 18.4 \\
COST_TOT (1000 NOK) & 5274.0 & 6832.0 & 12765.0 \\
\hline
\end{tabular}

The following efficiency indicators used in this study are defined as follows:

- DRG_DAY/MM_DAY (DRG-equivalents in the day-surgery unit per man-month in the surgical unit)

- DRG_TOT/MM_TOT (DRG-equivalents in the day-surgery division per manmonth in the surgical division)

- COST_TOT/DRG_TOT (Total cost per DRG-equivalents in the day-surgery division)

- OUT/MM_OUT (outpatients revenues in the day-surgery division per man-month in the outpatient division)

The summary results are presented in Table 3, and show average values for the variables for the three-month period for each hospital. It should be noted that variations during the months examined were higher in hospital $\mathrm{K}$ than in the other 
hospitals. One can understand from this that activity in hospital $\mathrm{K}$ was more sensitive than the two other hospitals (with RF units) to changes in the emergency rates.

Table 3: Efficiency in the three hospitals (average over three months), 1999

\begin{tabular}{lccc}
\hline & Hospital K & Hospital R & Hospital B \\
\hline DRG_DAY/MM_DAY & 3.7 & 6.5 & 5.9 \\
DRG_TOT/MM_TOT & 1.3 & 1.6 & 1.8 \\
COST_TOT/DRG_TOT & 29.0 & 22.9 & 21.5 \\
OUT/MM_OUT & 35.2 & 23.6 & 34.1 \\
\hline
\end{tabular}

The first row describes efficiency in the day-surgery unit. The number of DRGequivalents per man-labor months in the hospitals with $\mathrm{RF}$ units ( $\mathrm{R}$ and $\mathrm{B}$ ) is considerably higher than in the hospital without such a unit $(\mathrm{K})$. On average, the work efficiency in the day-surgery units in the hospitals with RF units is around $75 \%$ higher than the work efficiency in the day-surgery unit in hospital K. This is probably an important reason why the total work efficiency in the surgical division is on average $30 \%$ higher (row 2) and costs per DRG- equivalents are 25\% lower (row 3) in hospitals B and $\mathrm{R}$ than in hospital $\mathrm{K}$.

However, if one examines the efficiency in the outpatient clinics within the surgical division (row 4), one observes that hospital $\mathrm{K}$ is slightly more productive than hospital B. Moreover, hospital B and $\mathrm{K}$ are around 45\% more productive than hospital $\mathrm{R}$. This is a puzzling result. The qualitative data indicate that the main reason for this is that hospital $\mathrm{R}$ has an especially large number of nurses working at the outpatient clinics compared to the number of physicians. Much of the nurses' work was secretarial work: assigning patients for operation and making post-surgery calls (daysurgery patients were phoned two weeks after surgery to follow up on the patient's recovery). When the chief of staff and the head surgeon of hospital $\mathrm{R}$ were interviewed, they stated that the problem was a recognized one. The outpatient clinic had a long waiting list. The RF unit created increased demand for post-surgery examination at the outpatient clinic, but since the surgeons were occupied in the RF unit they were unable to meet the demand for more outpatient consultations. The 
surgeons clearly stated that they preferred performing surgery in the RF unit rather than conducting the pre- and post-examination in the outpatient clinic. The hospital was working on a model where the patient could be admitted directly to the RF unit from primary care physicians.

Furthermore, the results from the case studies indicate (figures not shown) that hospital $\mathrm{R}$ had a higher level of physician efficiency compared to the two other hospitals, while hospital B had a higher level of nurse efficiency. This could be due to the variation in team or rotational organization; more nurses are needed in a rotational structure. The reason why different structures were chosen could be further explained by the location of the two hospitals and different recruitment patterns. Hospital B is located in the near vicinity of Oslo, in a high-cost living area where it is more difficult to recruit nurses. Hospital R, on the other hand, is located further away from Oslo and has more difficulties attracting physicians. Hospital $\mathrm{R}$ is also less specialized than hospital B, which is perceivably less attractive to physicians.

In sum, the results from the case study indicate that ring fencing has a positive effect on hospital efficiency. In-depth interviews indicate that the main reason for this is that RF units make the production of surgical activities more stable and predictable and allow for the optimal use of personnel.

To fully comprehend the effect of RF units, their impact on a hospital as a whole needs to be examined. How is the rest of the hospital affected by a highly productive unit? Does efficiency diffuse and inspire the whole organization or does it create bottlenecks and slack in its other parts? The case study highlights the importance of coordination between hospitals' various units and the need for a well-tuned organization. In the next section of this article the whole organizational population of Norwegian hospitals is analysed and the effect of an RF unit on total hospital production and efficiency will be explored. 


\section{Panel data analysis - statistical specification}

\subsection{Efficiency indicators}

The findings from the data collected from all Norwegian somatic emergency hospitals will be tested to facilitate general comments. In contrast to the case study, this analysis will not separate the surgical division from internal medicine. Hence, the effect of RF units on the general efficiency, covering all activities, in a hospital is tested. Since hospitals are multi-productional organizations, the data envelopment analysis (DEA) is used to generate the measurement of cost-efficiency. DEA handles settings with multiple inputs and outputs more easily than other models do. Also, this approach does not require a specific functional form for the technology or specific distributional assumptions about the efficiency measure. DEA is sensitive to measurement errors. However, sufficient steps have been taken to secure the quality and accuracy of the data used in this analysis. The DEA framework originates from Farrell (Farrell 1957) and was further developed for piecewise linear technologies by Färe and Lovell (Färe and Knox Lovell 1978), Charnes, Cooper and Rhodes (Charners, Cooper, and Rhodes 1978) and Banker, Charnes and Cooper (Banker, Charnes, and Cooper 1984). DEA defines an efficiency frontier and relates other hospitals to that frontier.

Following other studies of cost-efficiency on Norwegian data (Biørn et al. 2003), hospital input is to be described by total operating expenses deflated to year 2000 prices. Hospital production (output) is described by two variables:

- Inpatient care: Inpatient care is measured as the number of discharges adjusted for case-mix by weighting discharges according to diagnostic related groups (DRGs) ${ }^{1}$.

- Outpatient care: Outpatient care is measured as the number of outpatient visits weighted by the fee paid by the state for each visit. Thus a hospital's revenues from outpatient care are an approximation of the volume of outpatient care adjusted for case-mix. Outpatient revenues are deflated to year 2000 prices.

Descriptive statistics for the variables in the DEA are presented in Table 4.

\footnotetext{
${ }^{1}$ The DRG register was first developed in the United States and categorizes the different diagnoses based on severity of the disease and estimated length of stay, indicating the level of resources needed to treat the patient (Magnussen 1986).
} 
Table 4 Descriptive statistics. Input and output variables in DEA. Mean (standard deviation), 1992-2000, $N=53$

\begin{tabular}{|c|c|c|c|c|c|c|c|c|c|}
\hline & 1992 & 1993 & 1994 & 1995 & 1996 & 1997 & 1998 & 1999 & 2000 \\
\hline $\begin{array}{l}\text { Total running } \\
\text { expenses (mill. NOK) }\end{array}$ & $\begin{array}{c}321.10 \\
(317.17)\end{array}$ & $\begin{array}{r}328.70 \\
(327.40)\end{array}$ & $\begin{array}{r}330.18 \\
(331.06)\end{array}$ & $\begin{array}{c}339.38 \\
(344.37)\end{array}$ & $\begin{array}{r}367.85 \\
(385.90)\end{array}$ & $\begin{array}{c}398.30 \\
(421.14)\end{array}$ & $\begin{array}{c}417.41 \\
(440.82)\end{array}$ & $\begin{array}{r}459.39 \\
(480.03)\end{array}$ & $\begin{array}{r}462.37 \\
(482.42)\end{array}$ \\
\hline $\begin{array}{l}\text { Inpatient care } \\
(1000 \mathrm{NOK})\end{array}$ & $\begin{array}{c}12842.61 \\
(12720.61)\end{array}$ & $\begin{array}{r}13246.78 \\
(13094.78)\end{array}$ & $\begin{array}{c}13280.11 \\
(13135.46)\end{array}$ & $\begin{array}{r}13767.27 \\
(13872.02)\end{array}$ & $\begin{array}{r}13880.42 \\
(13981.22)\end{array}$ & $\begin{array}{r}14236.74 \\
(14380.92)\end{array}$ & $\begin{array}{r}15032.54 \\
(15253.02)\end{array}$ & $\begin{array}{r}15484.79 \\
(15738.19)\end{array}$ & $\begin{array}{r}15631.83 \\
(15815.03)\end{array}$ \\
\hline $\begin{array}{l}\text { Outpatient care } \\
(1000 \mathrm{NOK})\end{array}$ & $\begin{array}{r}32340.84 \\
(36388.63)\end{array}$ & $\begin{array}{r}33134.73 \\
(38006.54)\end{array}$ & $\begin{array}{r}34035.34 \\
(38516.87)\end{array}$ & $\begin{array}{r}35419.76 \\
(40920.49)\end{array}$ & $\begin{array}{l}37543.68 \\
(4467.92)\end{array}$ & $\begin{array}{r}45013.09 \\
(52889.20)\end{array}$ & $\begin{array}{r}47130.97 \\
(56417.26)\end{array}$ & $\begin{array}{c}50973.61 \\
(62462.36)\end{array}$ & $\begin{array}{r}50617.04 \\
(60243.32)\end{array}$ \\
\hline
\end{tabular}

The efficiency frontier is based on a pooled set of observations (Harris, Ozgen, and Ozcan 2000). This is done in order to compare efficiency between years. Average levels of cost-efficiency are presented in Figure 1. The figure presents both average cost-efficiency for the whole sample, and average cost-efficiency for the hospitals that introduce RF units during the period.

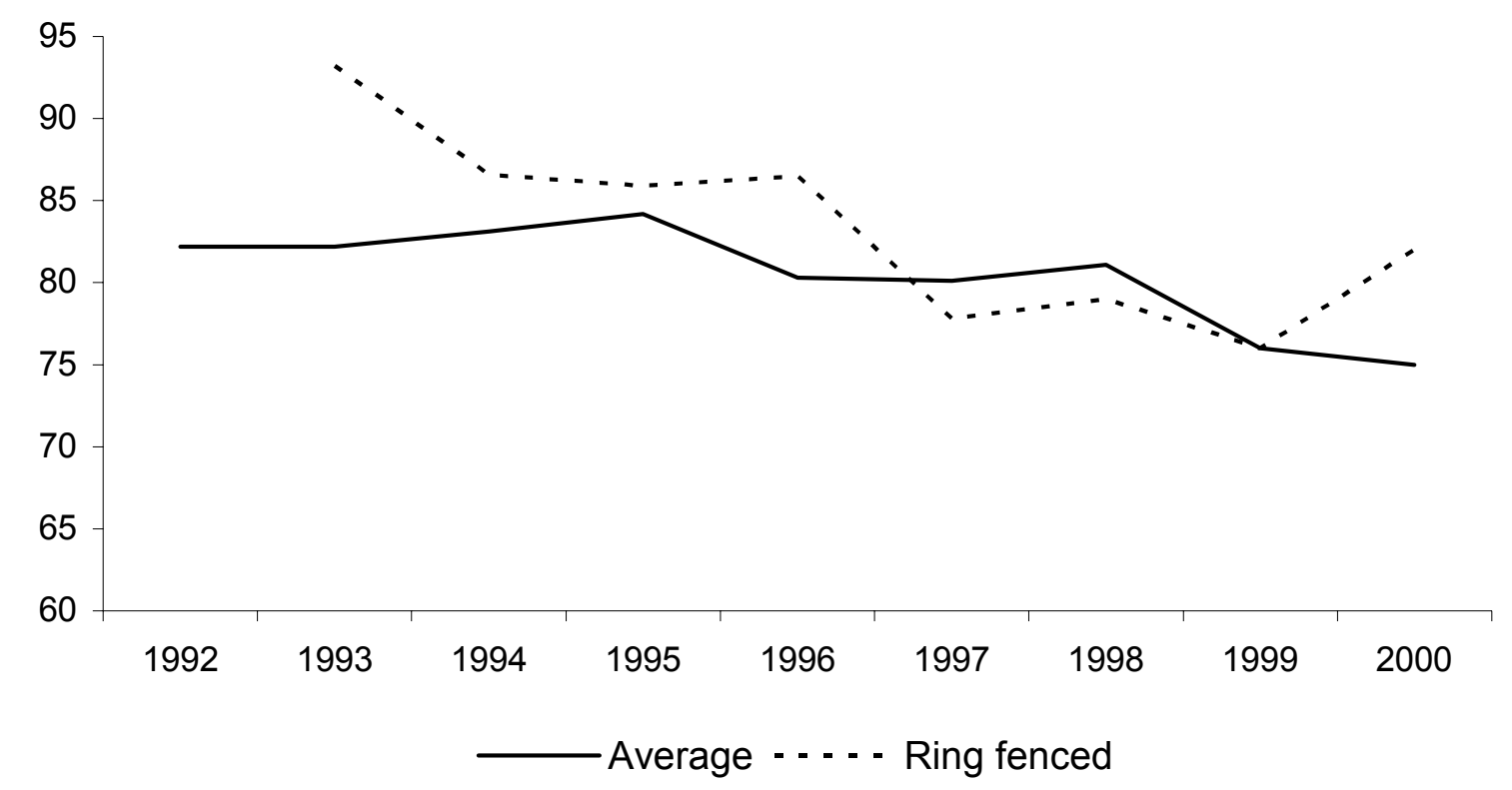

Figure 1 Cost-efficiency, somatic hospitals with alternative organization of surgical departments compared with average, 1992-2000, $N=53$ 
The number of hospitals with RF units increased during the 1990s: 1992: 0 hospitals, 1993:1 hospital, 1994: 1, 1995: 2, 1996: 3, 1997: 6, 1998: 9, 1999: 9, 2000: 11 hospitals. Thus, the level of efficiency among hospitals with ring fenced surgical units will to a large extent be affected by single hospitals in the first part of the period of examination. The two hospitals that introduced ring fencing during 2000 are classified as non-ring fenced hospitals both in Figure 1 and in the rest of the analysis.

Optimal levels of practice imply a level of 100. The average cost-efficiency in 2000 was around 76 , implying that hospitals on average are $24 \%$ below best practice levels. A substantial decline in average cost-efficiency was observed during the periods from 1995 to 1996 and from 1998 to 1999 . This is believed to be due to particularly large pay increases (Biørn et al. 2003).

\subsection{Statistical models}

The specification of our basic statistical model is grounded in a model developed by Biørn et al. (2002, see also (Hagen 1997)). It is assumed that hospital cost-efficiency (CE) is affected by the following six variables: size of hospital budget (BUD), type of contract between county and hospital in the current year (ABF), outpatient revenues as a share of total revenues (OUT), the share of long term stays (LONG), the number of surgical DRGs as a share of total numbers of DRGs (SHSURG), hospital size (BEDS) and ring fencing (RF). Table 5 shows the definitions of the variables and data sources.

\section{Table 5 Definitions of explanatory variables}

\begin{tabular}{|c|c|c|}
\hline Variable & Operationalization & Data source \\
\hline BEDS & Number of hospital beds & Statistics Norway \\
\hline BUD & Hospital's total revenues (accounting data)/BEDS & $\begin{array}{l}\text { SINTEF Unimed, } \\
\text { Statistics Norway }\end{array}$ \\
\hline OUT & (Outpatient revenues/Total hospital revenues)*100 & Statistics Norway \\
\hline LONG & $\begin{array}{l}\text { (Number of days with irregularly long length of stay/Total number of in-hospital } \\
\text { days)*100 }\end{array}$ & $\begin{array}{l}\text { Norwegian Patient } \\
\text { Register (NPR) }\end{array}$ \\
\hline SHSURG & (Number of surgical DRG-points/Total number of DRG-points)*100 & SINTEF Unimed \\
\hline RF & $\begin{array}{l}\text { Dummy variable that takes the value of } 1 \text { if the hospital has ring fenced a surgical } \\
\text { unit, } 0 \text { otherwise }\end{array}$ & $\begin{array}{l}\text { Center for Health } \\
\text { Administration }\end{array}$ \\
\hline $\mathrm{ABF}$ & $\begin{array}{l}\text { Dummy variable that takes the value of } 1 \text { if the hospital has an activity-based } \\
\text { contract with the county council the current year, } 0 \text { otherwise }\end{array}$ & $\begin{array}{l}\text { Center for Health } \\
\text { Administration }\end{array}$ \\
\hline
\end{tabular}


The number of beds (BEDS) is included to represent scale effects that are not captured by the DEA measures. The argument underlying BUD is that hospitals with large budgets would have relatively more slack resources and therefore more resources available for non-production related activities, such as research, teaching, or leisure. BUD is defined as total revenues standardized by the number of hospital beds to correct for differences in hospital size. As discussed earlier, outpatient revenues are included in the output vector in the efficiency analysis (DEA) to account for the number of outpatients. It is necessary to do this since data on the number of outpatients are lacking for many of the large hospitals in the period under analysis. However, outpatient revenues have both a price and a volume component. This is corrected for by including a variable measuring outpatient revenues as a share of total hospital revenues (OUT). Furthermore, a variable representing the share of patients with an irregularly long length of stay (LONG) is included to capture the possible effects of this on hospital efficiency. There are reasons to believe that LONG to a certain degree is beyond a hospital's control, and probably affected by the volume and composition of formal care for the elderly in the hospital catchment area ${ }^{2}$. The variable describing the number of surgical DRGs, as a share of the total number of DRGs (SHSURG), is included to describe variations in hospitals' patient mix. A variable describing day-surgery as a share of total surgery (both measured in hospital stays or DRG-equivalents) was not available until 1999. This will be reverted to later.

Activity-based financing (ABF) was introduced for $79 \%$ of hospitals from 1 July 1997, and then implemented over a five year period for the remaining hospitals. Traditionally, Norwegian hospitals have been financed by a lump-sum budget. In $1997,70 \%$ of the budget was given as lump-sum revenues, while $30 \%$ of the hospital budget was activity-based for the hospitals that introduced ABF. In 1998, activitybased payment was raised to approximately 45\% of the budget, in 1999 to approximately $50 \%$ of the budget, and in 2002 to $55 \%$ of the budget. ABF was introduced to fulfil the waiting list guarantee adopted by Parliament. 
Table 6 presents descriptive statistics for explanatory variables.

Table 6 Descriptive statistics, explanatory variables. Mean (standard deviation) per annum, 1992-2000, $N=53$

\begin{tabular}{lrrrrrrrrr} 
& 1992 & 1993 & 1994 & 1995 & 1996 & 1997 & 1998 & 1999 & 2000 \\
\hline \multirow{2}{*}{ BEDS } & 232.15 & 230.00 & 235.15 & 233.87 & 233.93 & 236.56 & 234.47 & 230.10 & 221.56 \\
& $(220.43)$ & $(220.13)$ & $(228.12)$ & $(228.77)$ & $(228.93)$ & $(235.71)$ & $(228.31)$ & $(225.72)$ & $(214.67)$ \\
BUD (mill. NOK) & 1.34 & 1.39 & 1.36 & 1.41 & 1.50 & 1.61 & 1.69 & 1.90 & 1.96 \\
& $(0.23)$ & $(0.22)$ & $(0.21)$ & $(0.20)$ & $(0.22)$ & $(0.23)$ & $(0.27)$ & $(0.31)$ & $(0.31)$ \\
OUT & 8.73 & 8.73 & 9.00 & 9.11 & 8.87 & 10.32 & 10.24 & 9.98 & 9.83 \\
& $(2.63)$ & $(2.62)$ & $(2.63)$ & $(2.84)$ & $(2.54)$ & $(2.47)$ & $(2.58)$ & $(2.69)$ & $(2.46)$ \\
LONG & 33.96 & 29.47 & 27.29 & 25.53 & 24.47 & 22.40 & 22.90 & 24.36 & 19.16 \\
& $(17.17)$ & $(15.88)$ & $(14.35)$ & $(13.46)$ & $(12.59)$ & $(11.16)$ & $(12.28)$ & $(12.05)$ & $(8.95)$ \\
SHSURG & 40.84 & 41.00 & 40.46 & 39.77 & 37.91 & 40.68 & 40.31 & 40.72 & 41.61 \\
& $(7.47)$ & $(6.51)$ & $(6.97)$ & $(7.27)$ & $(7.62)$ & $(7.92)$ & $(7.86)$ & $(8.24)$ & $(8.40)$ \\
RF & & 0.02 & 0.02 & 0.04 & 0.06 & 0.11 & 0.17 & 0.17 & 0.17 \\
& & $(0.14)$ & $(0.14)$ & $(0.19)$ & $(0.23)$ & $(0.32)$ & $(0.39)$ & $(0.38)$ & $(0.40)$ \\
ABF & & & & & & $0.49)$ & 0.87 & 0.92 & 0.98 \\
& 0 & 0 & 0 & 0 & 0 & $(0.48)$ & $(0.34)$ & $(0.27)$ & $(0.14)$ \\
\hline
\end{tabular}

The panel data allow one to distinguish between intra-hospital effects, i.e. effects for a specific hospital between different years, and inter-hospital effects, i.e. differences between the hospitals in a specific year. This analysis focuses on the intra-hospital effects. This is done by including hospital-specific terms to capture hospital heterogeneity. The fixed-effect models eliminate hospital-specific factors and give a strong and conclusive test of the effects of the variable describing the introduction of RF units. Furthermore, dummy-variables are included for years to account for unobserved time variations in all models. However, controlling for case- and timespecific heterogeneity in panel data analysis is also beset with a range of difficulties (Baltagi 2001). The conclusiveness of the results is therefore critically examined by considering different model specifications.

\footnotetext{
${ }^{2}$ How characteristics of the primary care services affect a patient stay in hospitals is shown in chapter five of this thesis
} 


\section{Results}

In order to examine the conclusiveness of the results, different model specifications and estimation methods are considered (Table 7). The first model presents results for the control variables only. Model 2, on the other hand, is a full model. To investigate the sensitivity of the results from Model 2 hospitals have been excluded casewise to check if this affects the results. Model 3 presents results where one specific hospital is excluded from the analysis.

Table 7: Cost-efficiency, Statistical models. Estimates (panel corrected std. errors in parentheses)

\begin{tabular}{lccc}
\hline & Model 1 & Model 2 & Model 3 \\
\hline C & $60.456(6.241)^{* * *}$ & $60.386(6.250)^{* * *}$ & $60.343(6.133)^{* * *}$ \\
BEDS & $-0.031(0.011)^{* *}$ & $-0.032(0.011)^{* * *}$ & $-0.032(0.011)^{* * *}$ \\
BUD & $-9.850(1.769)^{* * *}$ & $-9.881(1.772)^{* * *}$ & $-10.057(1.747)^{* * *}$ \\
OUT & $2.314(0.201)^{* * *}$ & $2.320(0.202)^{* * *}$ & $2.313(0.198)^{* * *}$ \\
LONG & $0.059(0.030)^{* *}$ & $0.060(0.030)^{* * *}$ & $0.064(0.029)^{* *}$ \\
SHSURG & $0.250(0.745)^{* * *}$ & $0.250(0.074)^{* * *}$ & $0.261(0.073)^{* * *}$ \\
RF & - & $0.408(0.998)$ & $1.924(1.037)^{*}$ \\
ABF & $2.379(0.938)^{* * *}$ & $2.388(0.939)^{* * *}$ & $1.877(0.947)^{* * *}$ \\
Dummies for hospital & Yes & Yes & Yes \\
Dummies for year & Yes & Yes & Yes \\
-2 Res Log likelihood & 2417.2 & 2415.2 & 2352.6 \\
& & & \\
\hline
\end{tabular}

Model 1: The variable ring fencing is excluded

Model 2: Full model

Model 3: Full model but hospital $R$ is excluded from the analysis

$* P<0.10 ; * * P<0.05 ; * * * P<0.01$

The control variables show stable effects when the different models are compared. Hospital size (BEDS) has a slightly negative effect on cost-efficiency in all models, indicating that large hospitals have higher costs compared to smaller hospitals. Hospital budget (BUD) shows an expected effect, being in accordance with results from earlier studies (Hagen, Iversen, and Magnussen 2001). Higher budgets reduce cost-efficiency as it is defined in this analysis. The interpretation is that high budgets imply that resources can be used for activities other than patient treatment. A higher share of outpatient revenues (OUT) seems to increase hospital efficiency. This can be a consequence of the structural differences in hospital organization. A higher share of patients treated in outpatient clinics implies shorter stays at hospital and the need for 
fewer resources for hospital care. The direction of the estimate from the variable LONG, however is contrary to expectations. The introduction of $\mathrm{ABF}$ does, nonetheless, increase efficiency as expected and the estimates are roughly in accordance with those from Biørn et al. (2002).

The variable describing ring fencing (RF) is included in Models 2 and 3. In Model 2, the effect is positive, although statistically insignificant. When the data were closer examined it was found that hospital $\mathrm{R}$ had a negative effect on the results. When hospital $\mathrm{R}$ was excluded from the analysis (Model 3), a positive and statistical significant effect incurred by ring fencing. The results were surprising since hospital $\mathrm{R}$ has received special attention because of its $\mathrm{RF}$ unit and has been referred to as a successful hospital by several official reports. A closer inspection of hospital $\mathrm{R}$ illustrated that the hospital was in a downturn in the period until the introduction of the RF unit. Figure 2 depicts cost-efficiency for hospital R in the period from 1992 to 2002. The figure is based on the DEA analysis presented previously (Figure 1). As can be seen from the figure, the hospital recorded a decrease in efficiency the first five years of the period. It seems that the decline came to a halt in 1997 and then stabilized.

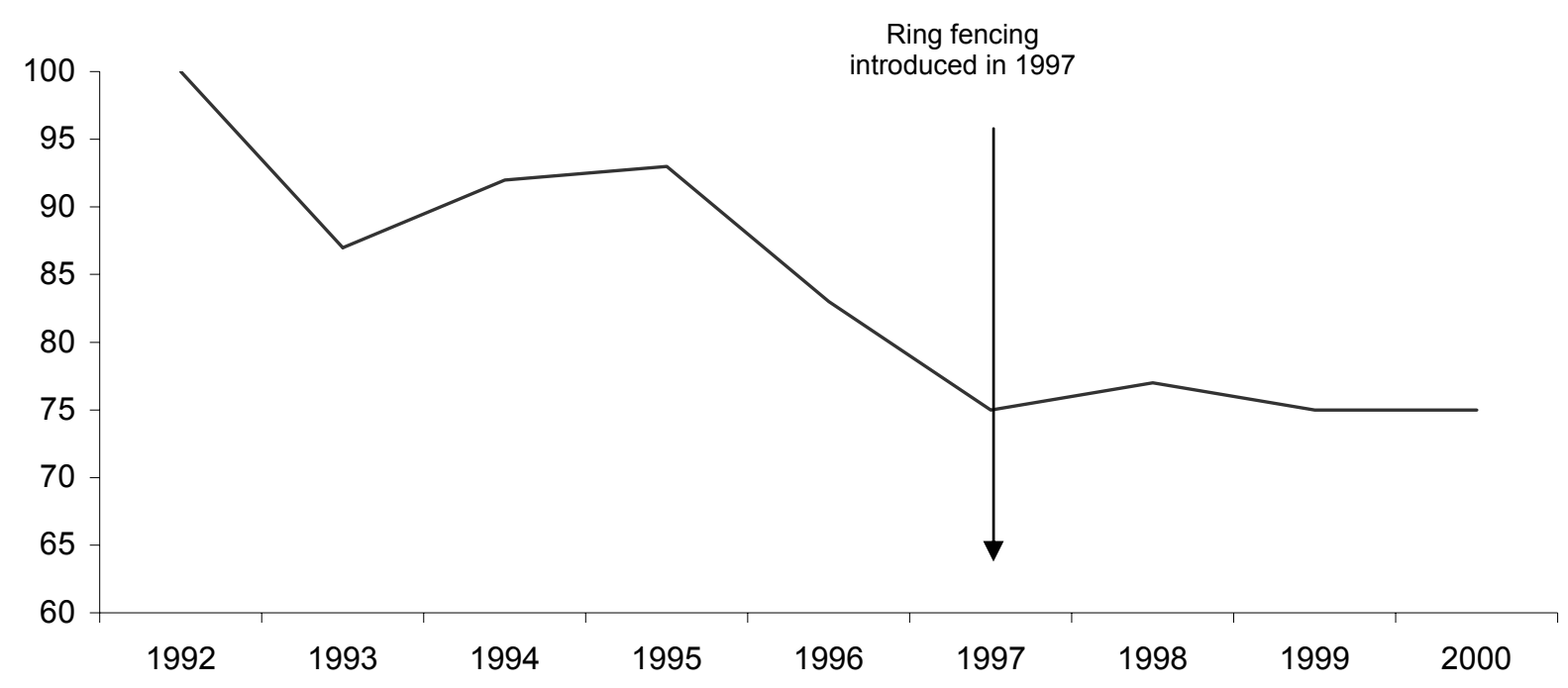

Figure 2 Cost-efficiency (CRS) hospital R from 1992 to 2000. Ring fencing unit introduced in 1997. 
The RF unit in hospital R has been operating since 1997, and although an increase in efficiency cannot be observed in the years since 1997, it could be said that the introduction of an RF unit was instrumental in reversing the negative trend.

Nevertheless, excluding a case from an analysis to make the estimates fit initial expectations is undesirable. The conclusion from the analysis above should therefore be that the introduction of RF units does not seem to increase hospital efficiency significantly even though the estimates are positive.

A re-estimation of the dataset for the years 1999-2000 was conducted with the variable describing day-surgery as a share of total surgery (both in DRG-equivalents) as an additional explanatory variable. The conclusion was that the share of daysurgery had a positive effect on hospital efficiency as showed by Midttun and Martinussen (Midttun and Martinussen 2002). A 10\% increase in day-surgery as a share of total surgery increased hospitals' cost-efficiency by approximately $2 \%$. The effect of RF in this extended model is positive but still statistically insignificant.

\section{Discussion and conclusion}

This analysis has investigated the effects on a hospital's efficiency of ring fencing of elective surgery at three different levels: at the day-surgery unit level, surgical division level and hospital level. The first two analyses were based on case studies from the three hospitals, while the third analysis was based on a panel data set including all Norwegian somatic hospitals in the period 1992-2000. The case studies indicated that work efficiency in ring fenced day-surgery units was 60-75\% higher than in day-surgery units without ring fencing. Although this difference can undoubtedly be explained by factors other than structural organization, the case study confirms a strong effect of ring fencing. At the surgical division level the effects are smaller, i.e. approximately $25-30 \%$. This is also a strong effect and indicates that the introduction of a ring fenced day-surgery unit in a surgical division can be done without increasing slack resources in other parts of the surgical division (cf. the 
discussion in the first section of this article). Ring fencing does not compete or interfere with ordinary surgical activity and allows the hospital to differentiate and better adapt surgical equipment and routines in order to handle less complicated surgery with less effort. However, the results from the panel data analysis at hospital level are discouraging; a positive effect of ring fencing on hospitals' cost-efficiency ranging from 0.4 to $1.9 \%$ was observed, but the effects are, in most versions of the statistical models, insignificant.

Some of the differences in the estimated effect between the three analyzed levels are easy to understand; since the day-surgery unit makes up a small part of the surgical division and the surgical division a small part of the hospital, the effect of RF units should decline with an increase in analytical levels. Yet, differences in work efficiency of $25-30 \%$ between surgical divisions are hardly insignificant in terms of their effect at the hospital level, if the case studies were reasonably representative for the sample of hospitals. The last assumption is of course questionable. Therefore, in the following it is speculated that the effects of RF units on hospital efficiency differ between hospitals for several reasons not fully captured by the statistical models used in this analysis.

It is the authors' belief that the effect of an RF unit is dependent on both external and internal conditions. The internal conditions describe how an RF unit is adapted to the rest of the hospital and how surgical procedures are performed. An RF unit is a specialization of the organizational structure of a hospital and must be adapted to the rest of its surgical activities as well as to the surgical activity performed in such a unit. Table 8 depicts possible alternatives in organizing surgical departments depending on the characteristics of the surgical procedures performed. The different categories are not exhaustive. The table gives a picture of how various structures are fitted into different internal conditions and surgical procedures. An operation theater in a university hospital is organized differently from an operation theater in a private specialist clinic to match the surgery performed. Briefly, the choice of organizational design depends on three internal conditions that must be considered: 1) The complexity or severity of the disease and the type of surgical intervention needed; 2) whether the disease is rare or common and; 3) the dependency on other services (laboratory, x-ray, intensive care unit, etc.). A hospital has to adapt its structural 
features to these characteristics. How well they perform depends on how well adapted the structure is to the activity. A complicating factor is that the structure also dictates the activity in as much as a given structure attracts different kinds of activity.

An RF unit represents a specialized structure, better equipped to handle certain procedures. The various structure types could possibly be even more differentiated.

Table 8 Different choices of organizational designs of surgical activity depending on characteristics of the procedure performed.

\begin{tabular}{c|c|c|c|c|}
\multicolumn{1}{c}{} & \multicolumn{2}{c}{ High complexity } & \multicolumn{2}{c}{ Low complexity } \\
\cline { 2 - 5 } Many cases & Few cases (rare) & Many cases & \multicolumn{1}{c|}{ Few cases (rare) } \\
\hline High dependency & $\begin{array}{c}\text { Ordinary surgical } \\
\text { theater }\end{array}$ & $\begin{array}{c}\text { University hospitals, } \\
\text { teaching }\end{array}$ & Ring fencing & $\begin{array}{c}\text { Mix elective and } \\
\text { acute patients, } \\
\text { teams with high } \\
\text { flexibility }\end{array}$ \\
\cline { 2 - 5 } & $\begin{array}{c}\text { ER (Emergency } \\
\text { room and GP on- } \\
\text { duty call) }\end{array}$ & $\begin{array}{c}\text { Public specialist } \\
\text { care }\end{array}$ & Outpatient clinic & $\begin{array}{c}\text { Private specialist } \\
\text { care }\end{array}$ \\
\hline
\end{tabular}

There is a recent tendency to establish more specialized structures such as RF units. However, if an RF unit were to be introduced in a hospital performing less complex surgery but with few cases, then perhaps mixed surgery with flexible teams would be more appropriate and efficient. A university hospital offering surgical interventions for rare diseases may be experimenting and testing new and unconventional methods, and therefore needs an organizational structure more adaptable to different equipment and techniques as well as a large operating theatre capable of hosting an audience of surgeons in training. An RF unit similar to an assembly line would not serve this purpose.

The external conditions describe how a hospital is associated to other hospitals' behavior. It might be rational for a few hospitals to introduce an RF type of structure, but if every hospital in Norway established an RF unit, there would probably be a patient shortage for certain surgical procedures. Both hospitals $\mathrm{R}$ and $\mathrm{B}$ reported problems in getting enough patients to have the ring fencing unit operate at full 
capacity, a problem that presumably increased after this study was completed. One explanation of the statistically insignificant effect of ring fencing could be that these units are vulnerable to periods of patient shortage. An ordinary surgical department is more flexible and can handle various types of patients, while the RF unit is designed to perform a certain volume of operations and personnel are not organized flexibly enough to address periods when there is a shortage of patients requiring day-surgery.

Another external condition is how elective surgery is financed. As mentioned earlier, Norway introduced activity-based financing in 1997, which provides incentives for a higher production of elective surgery. If the DRG reimbursement is reduced or adjusted, it might then become less attractive to have RF units. As was shown in the case study, hospitals R and B actually increased the resources used for day-surgery by building a special unit to perform day-surgery instead of using existing infrastructure. This is clearly a shift in priorities. Hospitals R and B, which have ring fencing units, use one third more resources on day-surgery than hospital $\mathrm{K}$ does which does not have ring fencing. Political authorities could shift this priority by changing the DRG reimbursement level.

The principle of ring fencing and the production-oriented assembly line have proven to be effective in industries other than the hospital sector. In fact, it is intuitively understood as an efficient way to organize activities and perhaps that is why so few studies have been made to document the effect of such specialization in hospitals. The problem, as has been outlined in this study, is that elective surgery cannot simply be seen as an isolated product. A hospital still has to perform other types of surgical procedures and still needs to give priority to emergencies and more complicated surgery. The effect is influenced by both internal and external conditions.

To conclude, the results from this analysis show that ring fencing could increase costefficiency but that this is not a necessary effect. An RF unit probably needs a high volume of referred patients to succeed. Unless this is the case, effects of an RF unit on hospitals' overall efficiency can be small or even counter-effective. 
1. Aaserud, Morten and Mari Trommald (2001) "Elective surgery - cancelations, ring fencing and efficiency," Tidsskr Nor Lageforen 121 (21): 2516-9.

2. Baltagi, Badi H. (2001). Econometric analysis of panel data. 2nd ed. Chichester: John Wiley.

3. Banker, R. D., A. Charnes, and W. W. Cooper (1984) "Some Models for Estimating Technical and Scale Inefficiencies in Data Envelopment Analysis," Management Science 30: 1078-92.

4. Bertalanffy, Ludvig von. (1956). General system theory. In General systems: Yearbook of the society for the advancement of general system theory. Vol. 1. Edited by Ludvig von Bertalanffy and Anatol Rapoport.

5. Biørn, Erik et al. (2003) "The effect of activity-based financing on hospital efficiency : a panel data analysis of DEA efficiency scores 1992-2000," Health Care Management Science 6: $271-283$

6. Charners, A., W. W. Cooper, and E. Rhodes (1978) "Measuring the Efficiency of Decision Making Units," European Journal of Operational Research 2: 429-44.

7. Färe, R. and C. A. Knox Lovell (1978) "Measuring the Technical Efficiency of Production," Journal of Economic Theory 19: 150-62.

8. Farrell, M. J. (1957) "The measurement of productive efficiency," Journal of the Royal Statistical Society (120): 449-60.

9. Hagen, Terje P. (1997) "Agenda-setting Power and Moral Hazard in Principal-Agent Relations: Evidence from Hospital Budgeting in Norway," European Journal of Political Research (31): 287-314.

10. Hagen, Terje P., Tor Iversen, and Jon Magnussen. (2001). Sykehusenes effektivitetsutvikling 1992-1999: Hvilke effekter ga innsatsstyrt finansiering? [Oslo]: Universitetet i Oslo Helseøkonomisk forskningsprogram.

11. Hand, R., P. Levin, and A. Stanziola (1990) "The Causes of Cancelled Elective Surgery," Qual Assur Util Rev (5): 2-6.

12. Harris, J., H. Ozgen, and Y. Ozcan (2000) "Do mergers enhance the performance of hospital efficiency?," JOURNAL OF THE OPERATIONAL RESEARCH SOCIETY 51 (7): 801811.

13. Hauge, Hans Nielsen (1999). Strøket av programmet. 82-7756-023-0Oslo, Senter for helseadministrasjon Universitetet i Oslo.

14. Hedenbro, J. L. et al. (2000) "Eine neue, zentralisierte und gestraffte Arbeitsstrujtur macht die Chirurgie effizienter. Die steigende Bedeutung der ambulante und Kurzzeitchirurgie für eine wirtschaftliche Chirurgie bei fellende Kosten.," Chirurgische Gastro enterologie (16): $75-80$.

15. Jørgensen, LN et al. (1991) "Cancelled Operations in an Orthopedic Departement," Acta Orthop Scand Suppl 62 (53).

16. Kjekshus, Lars Erik and Terje P. Hagen (2003) "'Ring fencing" of elective surgery: Does it affect hospital efficiency?," (Submitted to Health Services Management Research). 
17. Knight, C. (1987) "Why Elective Surgery is Cancelled," AORN J (46): 935-9.

18. Lacqua, MJ and JT Evans (1994) "Cancelled Elective Surgery: An Evaluation.," Am Surg (60): 809-11.

19. Macarthur, AJ, C. Macarthur, and JC Bevan (1995) "Determinants of Pediatric Day-surgery Cancellations," J Clin Epidemiol (48): 485-9.

20. Magnussen, Jon. (1986). DRG-systemet anvendelser og konsekvenser. Trondheim: SINTEF Unimed.

21. Midttun, Linda and Martinussen, Pål E. (2002). Day surgery and hospital efficency: Panel data analysis of Norwegian hospitals, 1999-2001. Trondheim, Paper presented at the 11th Norwegian National Conference in Political Science, Trondheim. SINTEF Unimed Health Services Research.

22. Mintzberg, Henry. (1983). Structure in fives : designing effective organizations. Englewood Cliffs, N.J.: Prentice-Hall.

23. Monden, Yasuhiro. (1998). Toyota production system : an integrated approach to just-in-time. 3rd ed. Norcross, Ga.: Engineering \& Management Press.

24. Morrissey S, T. Alun-Jones, and S. Leighton (1989) "Why are operations cancelled?," BMJ (299): 778.

25. NOU. (1997). Pasienten først! Ledelse og organisering i sykehus (NOU 1997:2). Edited by Sosial- og helsedepartementet. Oslo: Statens forvaltningstjeneste Statens trykning.

26. Ross, DJ and SJ Watson (1988) "Cancellations in Elective Surgery - Are they Avoidable?," Health Bull (Edinb) (46): 106-9.

27. Taylor, Frederick Winslow. (1911). Scientific management. Westport, Conn.: Greenwood Press.

28. Thompson, James D. (1967). Organizations in action. Social science bases of administrative theory. New York: McGraw-Hill.

29. Ventura, JA and S. Radhakrishnan (2002) "Sequencing mixed model assembly lines for a JustIn-Time production system," Production Planning \& Control 13 (2): 199-210.

30. Wildner, M. et al. (1991) "Avoidable Causes of Cancelations in Elective Orthopaedic Surgery," Health Trends (23): 113-5.

31. Yin, Robert K. (1994). Case study research : design and methods. 2nd ed. Thousand Oaks, Calif:: Sage. 